Tyndall effect, it will allow fluorescein to pass through. Thus the fluorescein will give an earlier and more sensitive impression. i! bi

The most recent trends here are aimed at finding out the effect of pathological aqueous on a tissue culture of fibrocytes. It is suspected from clinical observations that the pathological humour will have a detrimental effect on these cells. The work has only just commenced (November, 1946) and no results are available yet.

The aqueous is now also being examined under the ultramicroscope to study the cells, bacteria, and the number and size of the protein particles.

\title{
BIBLIOGRAPHY
}

Amsler, M. et VerRey, FL.-De l'utilité pratique de la ponction de la chambre antérieure. Ophthalmologica, Vol. CV, Nr. 3/4 (1943).

VERREY, FLORIAN.-Un dispositif pour la centrifugation capillaire. Ophthalmologica, Vol. CV, No. $3 / 4$ (1943).

VERREY, FL. ET RENE DUFOUR.-Quelques aspects cytologiques de l'bumeur aqueuse dans les uvéites. Ophthalmologica, Vol. CVII, No. 1/2 (1944).

VERREY, FLORIAN.-Etude des éléments figurés de l'humeur aqueuse pathologique. -Librairie médicale F. Roth et Cie, Laus.

AMSLER, M. ET VERREY, FL.-Hétérochromie de Fuchs et fragilité vasculaire. Ophthalmologica, Vol. CXI, No. 2/3 (1946).

VERREY, FLORIAN.-Signification pratique de la phagocytose intraoculaire. Ophthalmologica, Vol. CXI, No. 4/5 (1946).

AMSler, M. und HUBER, A.-Methodik und erste klinische Ergebnisse einer Funktionsprüfung der Blut-Kammerwasserschranke. Ophthalmologica, Vol CXI, No. $2 / 3$ (1946).

HaEfeli, Walter.-Die Fluorescein-Permeabilität der Blut-KammerwasserSchranke des gesunden Auges. Ophthalmologica, Vol. CXII, No. 4/5 (1946).

Huber, AlFRED.-Zum Tyndallphänomen in der Augenvorderkammer. Ophthalmologica, 1947.

Zur Pharmakologie der Blut-Kammerwasser-Schranke. Ophthalmologica, 1947.

\section{A GRÖNBLAD-STRANDBERG SYNDROME*}

BY

DR. SÜREYYA GÖRDÜREN

PROFESSOR OF OPHTHALMOLOGY, UNIVERSITY OF ANKARA

ANGIOID streaks are a rare form of retinal degeneration and are recognisable by a network of streaks varying in colour from reddish to dark brown. The two components of the syndrome, that is, angioid streaks and pseudo-xanthoma elasticum could be clearly seen in our case. It is suggested that in this disease there is a degeneration of the elastic tissues throughout the body.

* Received for publication, January 18, 1947. 


\section{Case Report}

Hüseyin K., a worker aged 35 years, complained of blindness in the right eye and was admitted to hospital. He had never before noticed anything strange about his eyes. Personal and past history had no bearing on the case. We questioned him carefully but could not find any trace of a similar eye disease in any relative. Urine analyses showed nothing pathological, arterial blood pressure 70/100 m.m., red and white B.C. number, blood picture and internal organs were normal. Radiological examination of the lungs revealed nothing pathological. Mantoux test and Wassermann reaction were negative, blood cholesterin normal. Externally both eyes were normal. In the right eye central vision was lost, and in the fundus there was a second network behind the retinal vessels, resembling the latter (Fig. 1). Round the papilla was a black, irregulàr ring from which started many irregular streaks, with ragged borders and of varying width. The streaks were behind the retinal vessels and in front of

RIGHT

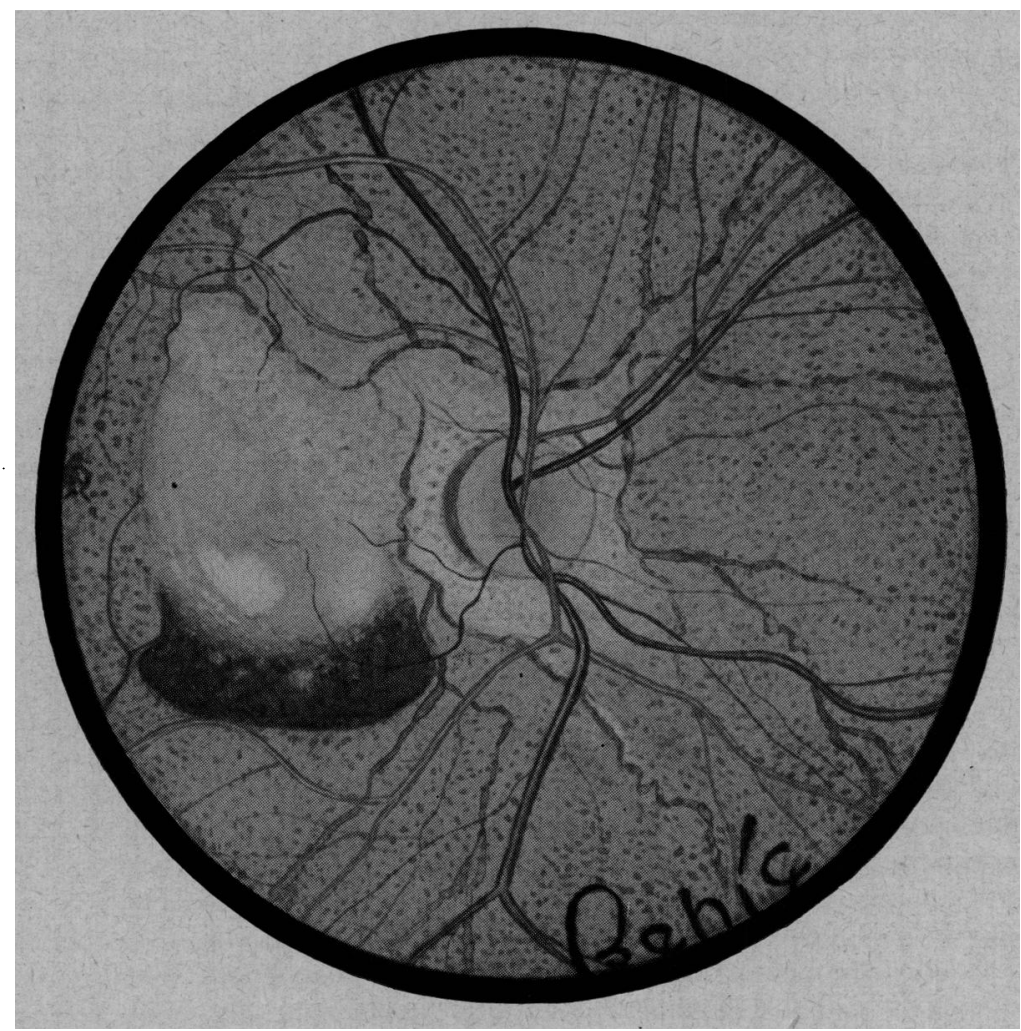

FIG. 1. 
the choroidal ones. The fundus picture did not reveal whether they belonged to the retina or choroid. Although the streaks usually ended before reaching the peripheral parts of the fundus, some could be seen to meet it. There was a large yellow lesion in the fundus, extending $1 \mathrm{~mm}$. into the vitreous, filling the macular area and reaching the papilla. The lower part of the lesion was surrounded

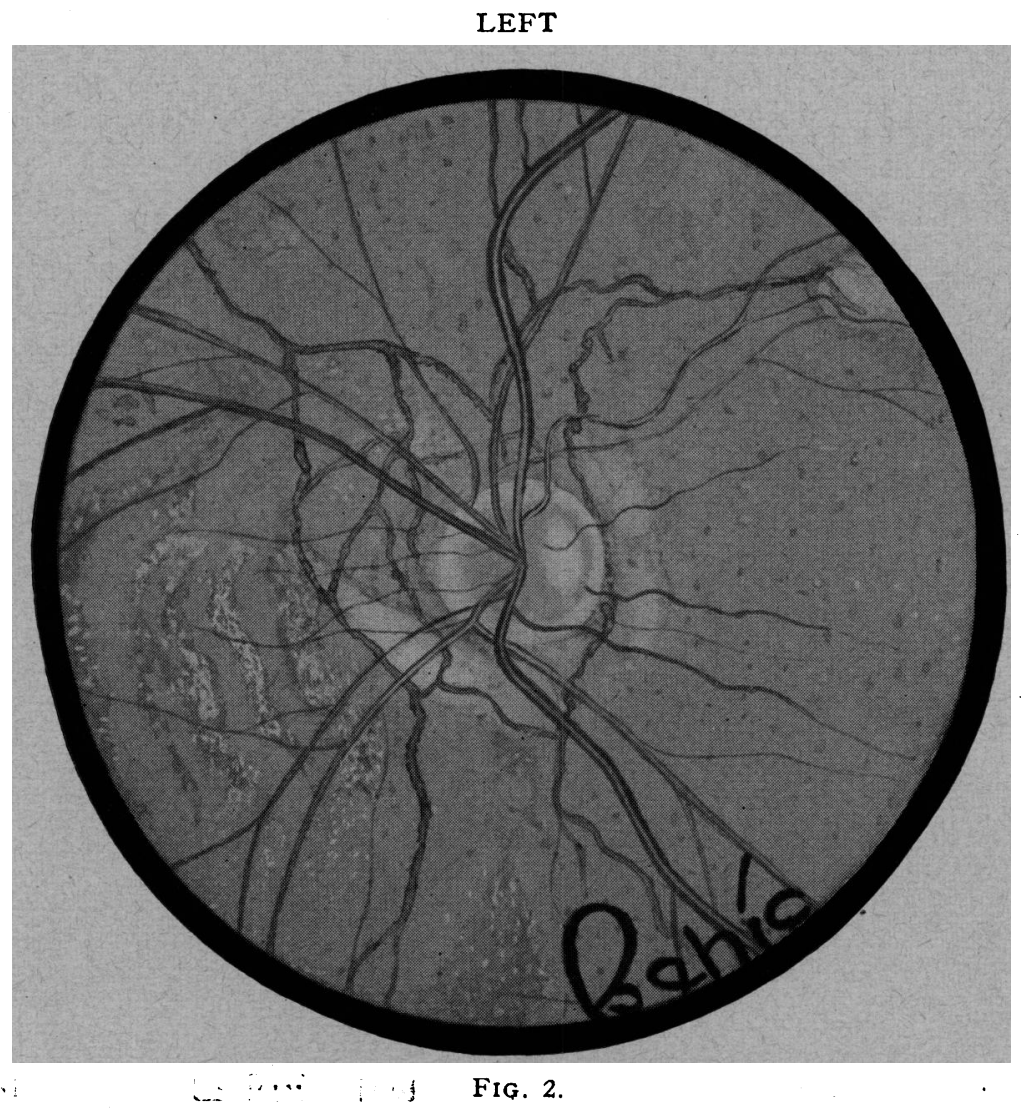

by a deep retinal haemorrhage. Near a small artery was a second small haemorrhage, temporal to the macular region. Since the patient had no central vision in the right eye, we obtained its visual field by the Schlosser method. A large central scotoma was revealed (Fig. 3). The left fundus was also abnormal with pigmented streaks as in the right eye, starting from the peripapillary ring and leading to the peripheral parts of the fundus. There were more streaks than in the right eye (Fig. 2). There were three choroidal atrophic patches round the papilla. No macular lesion was present, vision 
was 20/25 and visual field normal (Fig. 4). Only macular lesions interfere with vision. Pigmented lines do not apparently affect it.

In 1889 Doyne described the characteristic appearance of the fundus as a network similar to the vessels. Three years later the disease was observed by Plange, Stephenson and Knapp, and named angioid streaks as a clinical entity. The aetiology of the disease is

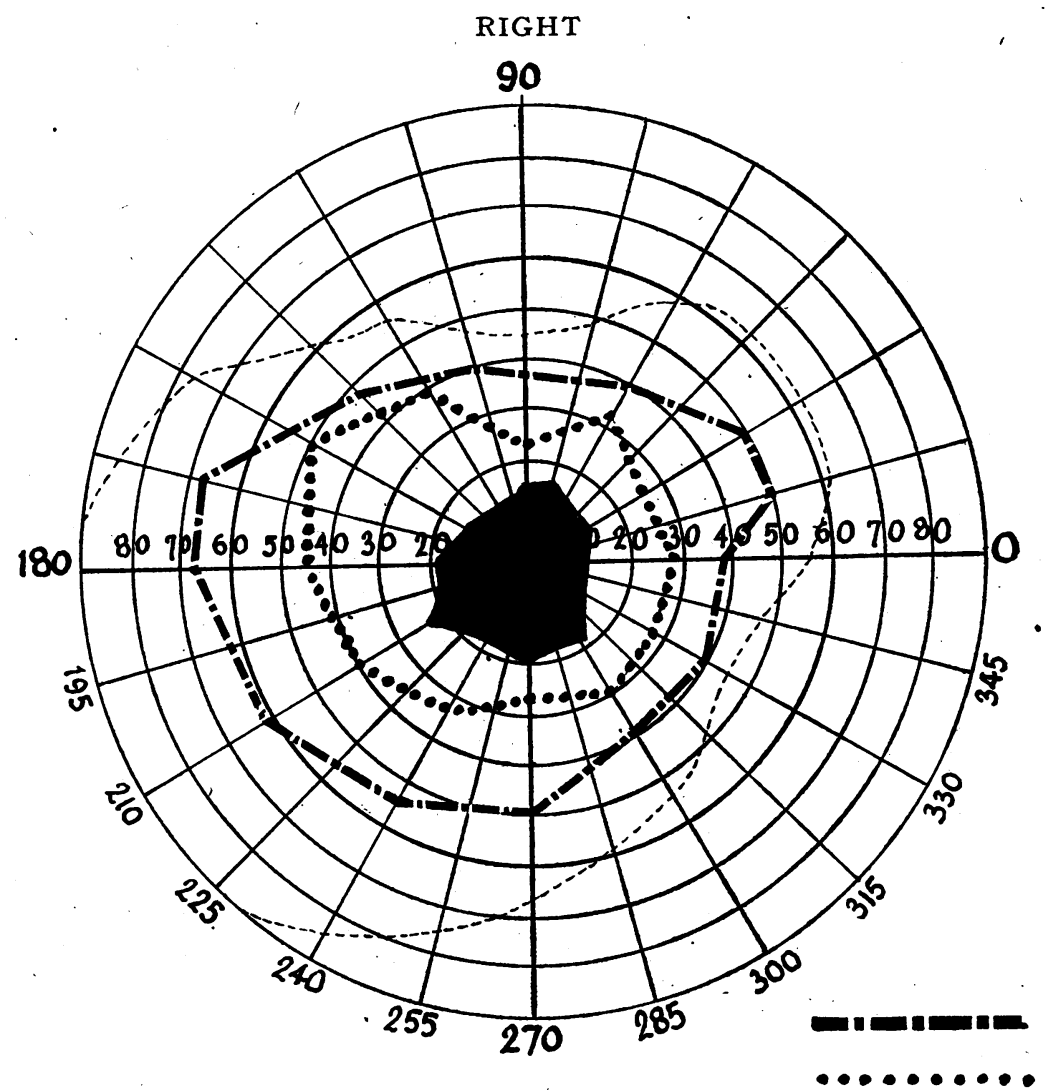

Fig. 3.

not well known. Doyne and Plange suggested that the streaks were haemorrhagic in origin and this was elaborated by Collins. $\mathrm{He}$ believed that the haemorrhage was intra-choroidal and that haematogenous pigment was deposited in the perivascular spaces.

The formation of supernumerary new vessels was suggested by Lister and others. Both theories were nevertheless found unsatisfactory.

The deformation of the inner tissues of the eye, particularly of the pigment epithelium, was suggested by Walser, Alt, Coppez, and Danis, the folding being probably produced by some exudative 


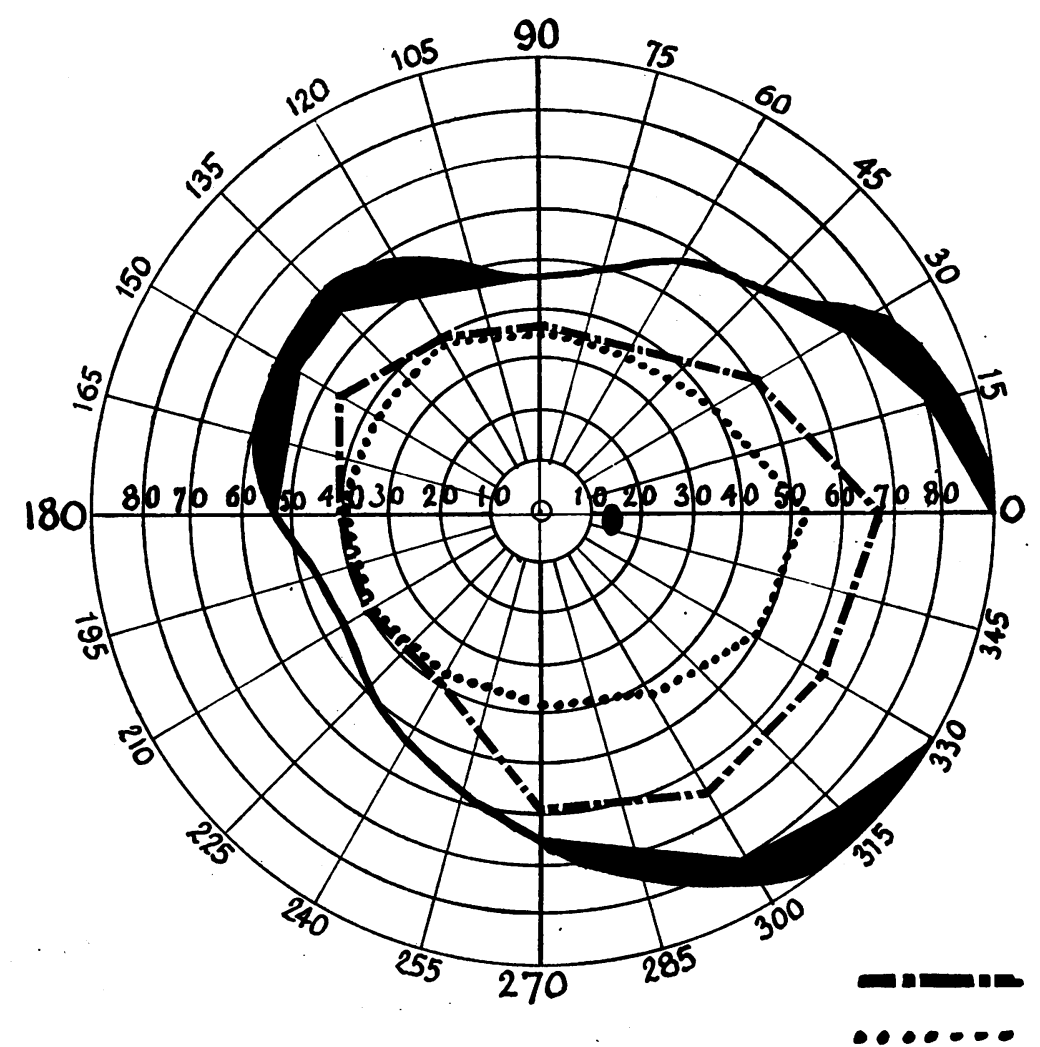

FIG. 4.

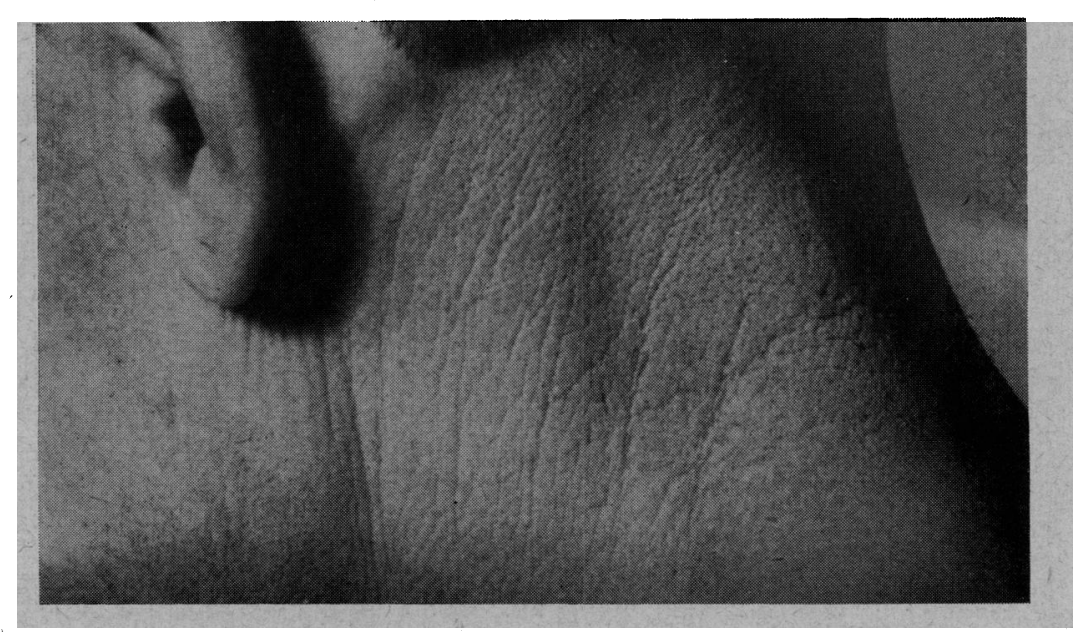

FIG. 5. 
process in the choroid. Affection of the retina itself by the accumulation under it of pigmentary debris is more fully authenticated by Law's histological findings. This theory, however, was also unsatisfactory.

Deterioration of the elastic elements of Bruch's membrane leading to the formation of fissures was suggested as the aetiological factor by Kofler and Lohmann. The theory attracted little attention, however, until the association of angioid streaks with pseudo-xanthoma elasticum was pointed out by Grönblad.

Our conclusions are in accordance with the last theory. It is a most uncommon disease of obscure aetiology, affecting the elastic tissues throughout the body.

The skin lesions, pointed out by Grönblad, have the appearance of buff or yellow patches situated on the neck, abdomen, flexures and chest. The first two manifestations were apparent in the abovementioned case. The presence of two conditions together was later observed in many cases. Statistics of Grönblad revealed the fact that 57 out 67 cases skin and fundus appearances together. The association of two lesions was given the name of GrönbladStrandberg syndrome.

Angioid streaks are caused by the widespread degeneration of the elastic tissues, and can be observed in the posterior pole and in the lamina vitrea. In the elastic structure of the lamina vitrea and in the inner layers of the choroid one may observe some degenerate patches, These patches appear to be due to the reduced resilience of the elastic tissue and may result in fissures and lines. In our case extensive parts of the skin of the neck and the abdomen had a

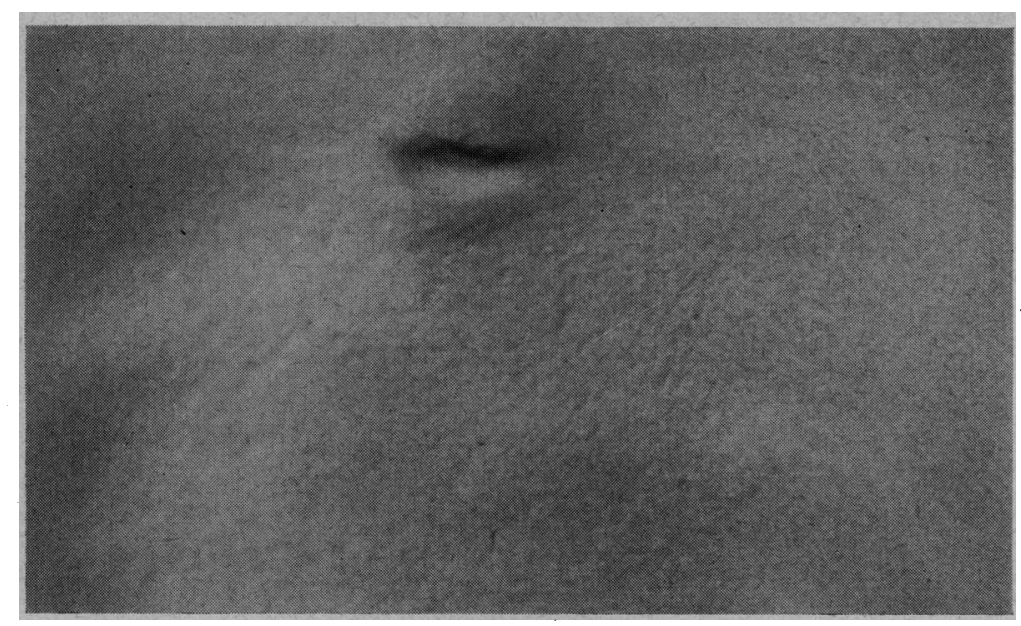

FIG. 6. 


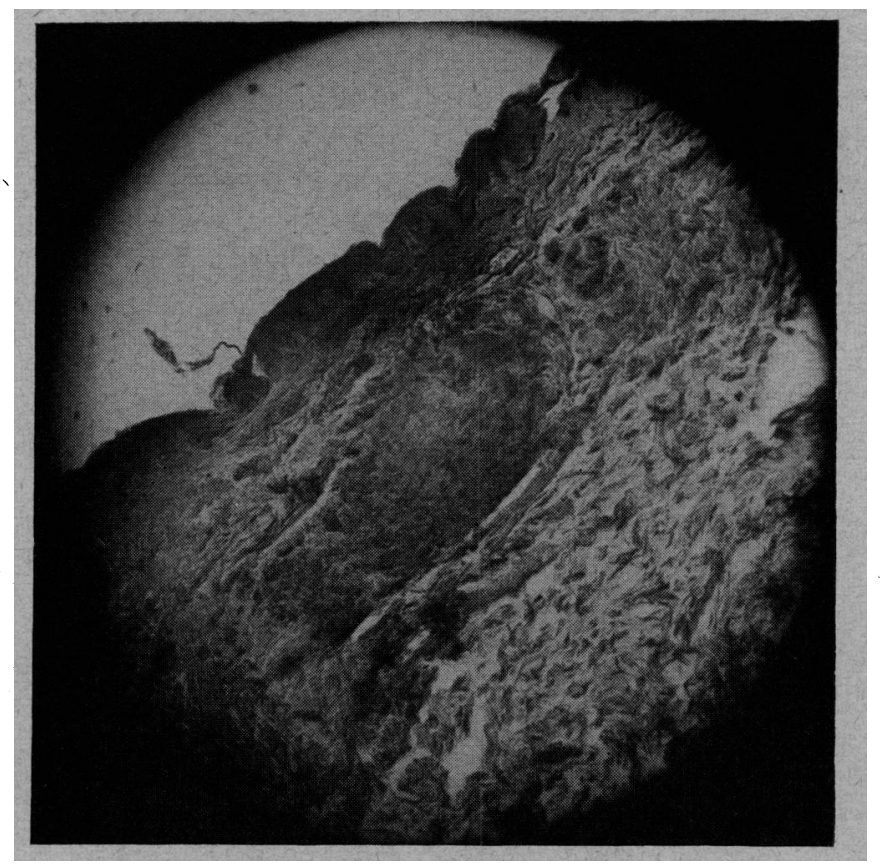

FIG. 7.

parchment-like appearance, and raised yellow streaks and patches could be clearly seen (Figs. 5-6). Although trauma has been quoted as an aetiological factor, no trauma could be noticed in this case.

Pathological examinations were made of the skin of the abdomen:"A slight hyperkeratosis may be observed in some parts, and an increase in pigmentation in others. In comparison the epidermis has become thinner, and shows accumulations of large protoplasmic vacuolar cells. The collagen fibres have been broken and diminished in size. Scattered infiltrations of inflammatory cells appear in some parts. "Anatomico-Pathological Laboratory, Gülhane Hospital (Fig. 7).

The above findings confirm the degeneration of the elastic elements of skin. Our case, having characteristic ophthalmoscopic and skin lesions, is a typical example of the so-called Grönblad-Strandberg syndrome.

\section{REFERENCES}

DUKE-ELDER-Text-book of Ophthalmology, Vol. III. BAILliaRT, P.-Traité d'Ophtalmologie, Vol. V. SCHIECK, F. - Kurzes Handbuch der Ophthalmologie.

MARChIONINI ALFRED UND TURGUT KEMAL-Dermatologische Wochenschrift Bd. 114, Nr. 8. 